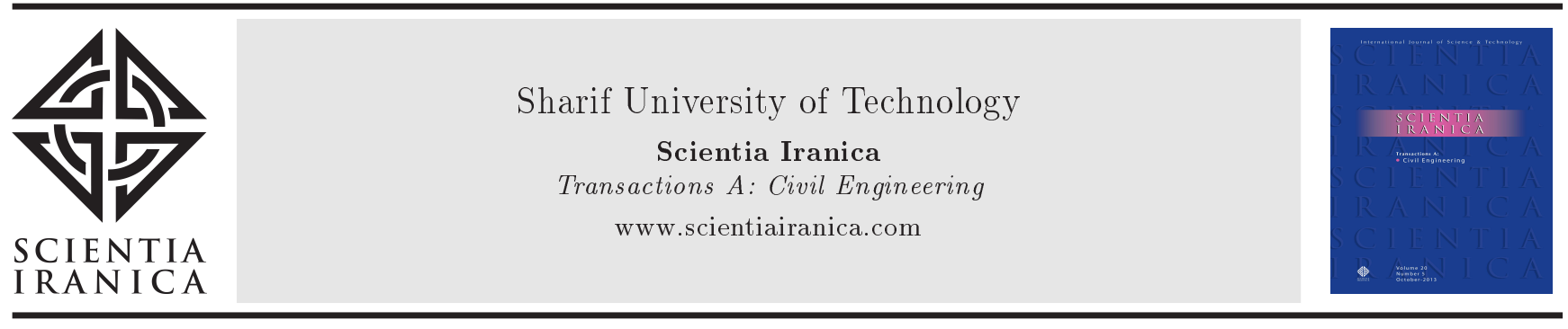

\title{
Modeling labor productivity in construction projects using hybrid SD-DES approach
}

\author{
S. Moradi ${ }^{\mathrm{a}}$, F. Nasirzadeh ${ }^{\mathrm{b}, *}$ and F. Golkhoo ${ }^{\mathrm{c}}$ \\ a. Department of Project and Construction Management, School of Art and Architecture, Tarbiat Modares University (TMU), \\ Tehran, Iran. \\ b. Department of Civil Engineering, Faculty of Engineering, Payame Noor University (PNU), P.O. Box 19395-3697, Tehran, Iran. \\ c. Department of Building, Civil \& Environmental Engineering, Faculty of Engineering and Computer Science, Concordia \\ University, Montreal, Canada.
}

Received 5 November 2015; received in revised form 5 January 2016; accepted 10 October 2016

\section{KEYWORDS \\ Productivity; \\ Construction \\ simulation; \\ Hybrid simulation; \\ System dynamics; \\ Discrete event \\ simulation.}

\begin{abstract}
Labor productivity is one of the most significant factors in the evaluation of the performance of construction projects. Improvement of labor productivity is believed to have direct impact on outperformance of the project. This research argues about a hybrid SDDES approach to model labor productivity considering the effects of both the context and operational level factors. The complex inter-related structure of different context factors affecting the labor productivity is modeled using System Dynamics (SD) approach. Discrete Event Simulation (DES) is implemented to model the operational variables and their effects on labor productivity. Using the proposed hybrid SD-DES model, the labor productivity can be determined more precisely since the effects of both context and operational variables are taken into account. The proposed hybrid model is implemented in a real-world case and the value of labor productivity is simulated considering the effects of both context and operational variables.
\end{abstract}

(C) 2017 Sharif University of Technology. All rights reserved.

\section{Introduction}

Economists and accountants consider productivity as the ratio between total input of resources and total output of product whilst project managers and construction professionals define productivity as a ratio between earned work hours and expended work hours, or work hours used [1-3]. Since construction activities are normally labor-intensive, productivity is frequently referred to as labor productivity [4].

Labor productivity is one of the most significant

\footnotetext{
*. Corresponding author.

E-mail addresses: pmcmoradi@gmail.com (S. Moradi);

f.nasirzadeh@gmail.com (F. Nasirzadeh);

f.golkhoo@gmail.com (F. Golkhoo)
}

doi: $10.24200 /$ sci.2017.4171 parameters in the evaluation of the performance of construction projects. Moreover, sometimes about 50 percent of the total cost of project is consumed for labor; thus, focus on increase in productivity can lead to a big save in overall costs $[5,6]$. Project processes are highly affected by labor productivity due to the dependence of cost estimating, scheduling, and operation plan on the labor productivity. Productivity can also play an important role in quality of projects; therefore, the management of labor and its productivity is crucial for determining the success of a construction project [1].

In construction, labor productivity is affected by both context and operational parameters. Here, context represents the overall construction-related behavior (e.g., staff skill level, collaboration level, motivation, inspection level, etc.), which dynamically interacts with operations and changes as a result of the feedback 
between the two. On the other hand, operational factors refer to process-related factors (e.g., sequence of operations, number of resources, resource assignment scheme of the processes, etc.), which affect the duration of executing the process and, consequently, the productivity. To model labor productivity considering all the influencing factors, both context and operational parameters should be taken into account.

The productivity model of construction labor has been studied since 1940 and this technique is still being improved [7]. Zayed and Halpin [8] used linear regression to assess the productivity. Pan [9] estimated the impact of weather conditions on productivity and duration by a fuzzy based model. Song and AbuRizk [4] proposed a systematic approach for measuring productivity and collecting historical data and modeled productivity by a combined neural network (ANN) and DES method. Watkins et al. [10] represented an agent based model to show the relationship between congestion and labor efficiency. Goodrum et al. [11] developed a model based on analysis of variance (ANOVA) and regression analysis to represent longterm improvements in labor productivity of activities due to experiencing significant changes in material technology. Goodrum et al. [12] developed a four staged predictive model based on Analytic Hierarchy Process and historical analysis to estimate the impact of new technologies on productivity. Mawdesley and Al.Jibouri [13] conducted a survey to identify influencing factors on productivity and modeled their relative influence on the productivity. Alvanchi et al. [14] introduced an approach for improving the productivity in construction projects by adjusting working hours and developed a hybrid SD-DES model for estimating expected productivity during different hours of overtime. Forcael et al. [15] studied productivity level during construction of transportation projects by simulating different buffering strategies in inventory, capacity, and time buffers. Nasirzadeh and Nojedehi [2] conducted a survey to identify influencing factors on labor productivity in construction and proposed a System Dynamics (SD) model to capture complex relationships between identified factors and estimate expected labor productivity considering the effects of identified factors.

The previous studies attempted to model the effects of one or some of the influencing factors on the labor productivity while, to have a comprehensive measurement of labor productivity, all affecting factors should be considered. Also, regarding the nature of factors influencing productivity, they are not able to account for the effects of both context and operational influencing factors. It is therefore believed that none of the previous research studies evaluate the value of labor productivity accurately.

In order to cover the mentioned gap, this re- search proposes a hybrid SD-DES approach to model labor productivity considering the effects of both the context and operational factors. The complex interrelated structure of different context factors affecting the labor productivity is modeled using System Dynamics (SD) approach. DES is implemented to model the operational variables and their effects on labor productivity. The required steps to develop the hybrid SD-DES model and synchronization of SD and DES methods are illustrated. The proposed hybrid SD-DES model would be able to estimate fluctuations of labor productivity considering the variations of context and operational influencing factors simultaneously. Using the developed hybrid SD-DES model, consequences of various managerial policies on labor productivity can be evaluated more precisely. The findings are expected to enhance understanding of the impact of various internal and external factors on the labor productivity performance. Finally, the proposed hybrid model is implemented in a real-world construction project and the value of labor productivity as well as the effects of different managerial policies is simulated considering the effects of both context and operational variables.

\section{Research methodology}

\subsection{System dynamics}

System Dynamics (SD), introduced by Forrester [16], is an objective-oriented simulation methodology enabling us to model complex systems considering all the influencing factors [17-19]. Much of the art of system dynamics modeling is discovering and representing the feedback processes, which along with stock and flow structures, time delays, and nonlinearities, determine the dynamics of a system [20]. All systems consist of networks of positive and negative feedback, and all dynamics arise from the interactions of these loops [20]. Negative loops are self-correcting and counteract change [20]; thus, they lead the system toward a balance. They are also called balancing feedback. Positive loops are reinforcing and make behavior of the system more disturbed [20].

Labor productivity in construction projects is influenced by various factors that have complex interactions with each other. System dynamics can account for the complex inter-related structure of different factors affecting labor productivity using cause and effect feedback loops [2]. Moreover, different managerial policies that could be implemented for the improvement of labor productivity could be modeled using SD approach. As a result, the effectiveness of managerial policies in improving labor productivity could be assessed before they are actually implemented.

\subsection{Discrete Event Simulation (DES)}

DES as a stochastic simulation tool can be used for 
analyzing construction processes. DES considers the project as a collection of construction processes; thus, by providing efficient detailed operational information, the repetitive operations would be represented in a structured single process. Duration of each operation is estimated using the historical data gathered from similar past operations. In construction, analysis of processes is complex in nature as the output from one operation usually acts as the input to another operation. It can therefore be estimated that how changes in the value of input factors of the predecessor operations affect the results of the following operations. Thereby, DES facilitates an efficient reduction in schedule complexity by representing the repetitive operations on a single process structure as well as capturing other detailed information, such as resources [21].

DES models the behavior of the system as a set of networks and queues. The DES modeling approach tries to model system behavior as its state evolves over time by following the system events, which are recognized as the change initiators in the state of the system [22]. Simulation of a process using DES can provide the value of productivity as well as the project duration taking account of the values of different operations duration, waiting times and delays, resource utilization, etc.

\subsection{Hybrid SD-DES simulation}

In the hybrid SD-DES modeling approach, capabilities of one model cover shortcomings of the other to provide more accurate results for system analysis [22]. To achieve more realistic assumptions, Discrete Event Simulation (DES) was used for modeling the operational parts of the system and System Dynamics (SD) for modeling the nonoperational parts of the system (i.e., feedback); this combination is called the hybrid SD-DES modeling approach [14,21-25]. Various types of hybrid modelling format among hierarchical, phase to phase, or integrated hybrid SD-DES format should be selected. For more details on the mechanism of the interactions between DES and SD parts, please refer to Moradi et al. [25]. After selection of the hybrid simulation format, the next step is to determine what should be exchanged between SD and DES. Formulation of synchronizing SD and DES models and essential interactions are done based on the principles proposed by Pritsker et al. [26]. Pritsker addressed three basic interactions in dealing with continuous and discrete variables synchronization: (1) A discrete change in a variable may cause a discrete change in other continuous variables; (2) A continuous change in a variable, by reaching a threshold, may cause a discrete change in interacting variables; and (3) A discrete change in a variable may change the functional description of a continuously changing variable. These principles can be traced in many construction system

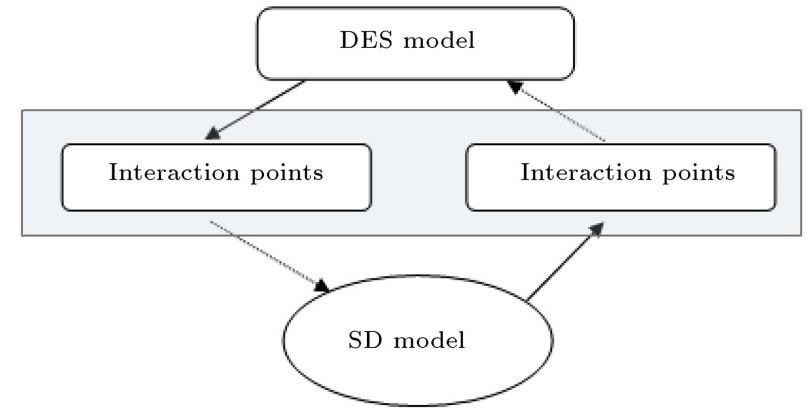

Figure 1. Mechanism of data exchange in hybrid SD-DES model.

modeling situations to define SD and DES interaction points. Interaction points are the variables whose values are changed or influenced by variables of the other model during hybrid simulation. Figure 1 shows the mechanism of data exchange between SD and DES parts of the hybrid model. Interaction points in each part of hybrid model (i.e., SD and DES) exchange data in predefined formats. The value of interaction points in SD can therefore be mapped into DES as an input, and vice versa.

\section{Model structure}

A flowchart representing different stages of modeling labor productivity using the proposed hybrid SD-DES approach is shown in Figure 2. As it can be seen in

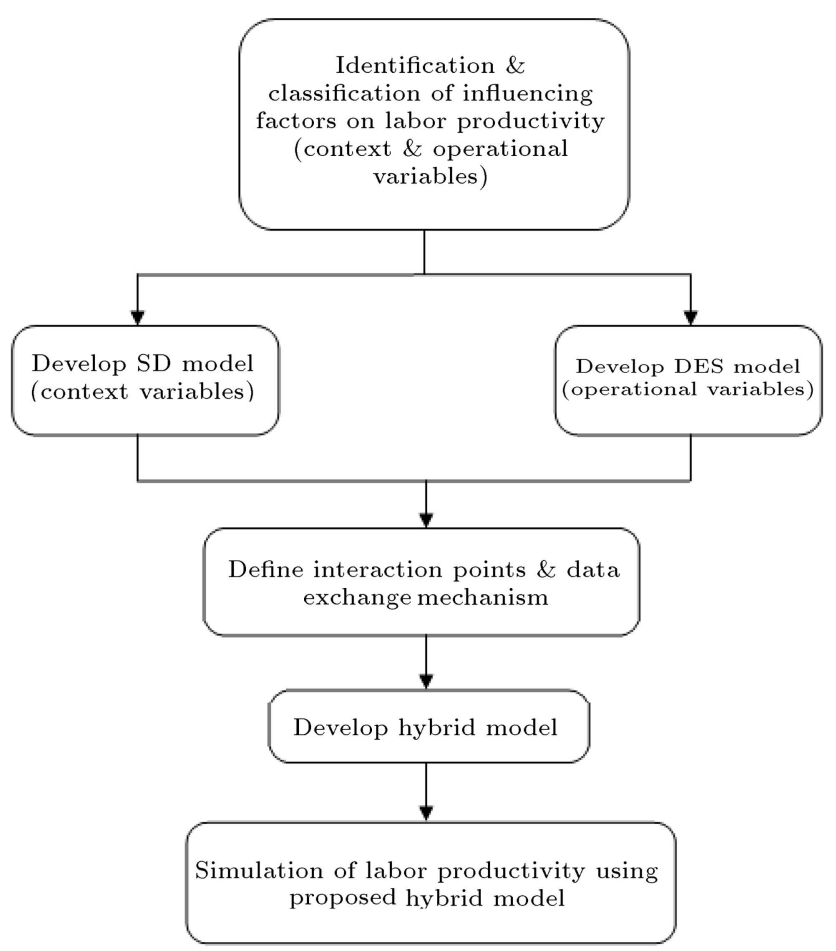

Figure 2. Flowchart of different stages of modeling labor productivity by the proposed hybrid SD-DES modeling approach. 
this figure, the proposed hybrid model tries to simulate the labor productivity considering all the influencing factors.

As mentioned before, labor productivity is affected by both context factors (e.g., staff skill level, motivation) and operational factors (e.g., number of resources, resource assignment scheme of the processes). Therefore, in the first step, all factors affecting labor productivity including both operational and context variables are identified and classified. Then, System Dynamics (SD) as an object oriented simulation methodology is used to capture dynamics of context variables taking account of their complex interactions. Discrete Event Simulation (DES) is utilized to analyze the effects of operational variables on labor productivity. The interaction points and data exchange mechanism between SD and DES models are selected. A hybrid SD-DES modeling method is then developed to integrate and synchronize SD and DES to model labor productivity considering both the context and operational variables. The labor productivity can finally be simulated using the proposed hybrid model.

In the following section, different phases of the proposed hybrid model will be explained in detail. System Dynamics (SD) and Discrete Event Simulation (DES) as the most popular traditional simulation tools are introduced and the need for a comprehensive hybrid model to integrate these simulation methods is discussed.

\subsection{Identification of influencing factors on labor productivity}

In this research, labor productivity is defined as the ratio of consumed man hours to work done. The labor productivity is affected by various factors. There are some previous studies that attempted to identify these influencing factors. Table 1 depicts different influencing factors identified by the previous studies [27-32].

Table 1. Different factors affecting the labor productivity.

\begin{tabular}{cl}
\hline Authors & \multicolumn{1}{c}{ The factors affecting labor productivity } \\
\hline & Lack of qualified supervisors, shortage of skilled labor, high rate of \\
Lim and Alum (1995) & labor turnover, labor absenteeism, and communications with foreign \\
& laborers.
\end{tabular}

Zakeri et al. (1996)

Kaming et al. (1997)

Sonmez and Rowings (1998)

Hanna et al. (1999)

Enshassi et al. (2007)

Jarkas and Bitar (2012)
Materials shortage, weather and site conditions, equipment breakdown, drawing deficiencies/change orders, and lack of proper tools and equipment.

Lack of material, lack of equipment, interference, absenteeism, supervision delays, and rework.

Percentage of overtime work, crew size, work quantity, job type, percentage of laborers, work characteristics, and factors in equipment component.

Order changes, work sequencing, work shifting, schedule compression, overtime work, absenteeism and turnover, labor problems, trade stacking, and material problems.

Material shortages, lack of labor experience, lack of labor surveillance, misunderstandings between team members, work change orders, payment delays, labor disloyalty, inspection delay, working without taking holidays, tool and equipment shortages, rework, misuse of time schedule, accidents, labor dissatisfaction, and supervisors' absenteeism.

Clarity of technical specifications, the extent of variation/change orders during execution, coordination level among design disciplines, lack of labor supervision, proportion of work subcontracted, design complexity level, lack of incentive scheme, lack of construction manager's leadership, stringent inspection by the "engineer", and delay in responding to "Requests For Information" (RFI). 
Table 2. Different operational and context factors affecting labor productivity.

\begin{tabular}{cl}
\hline Type & \multicolumn{1}{c}{ Influencing factors } \\
\hline Context (continuous) & $\begin{array}{l}\text { Supervision, weather conditions, job complexity, lack of } \\
\text { working area, labor experience (skillfulness), motivation, } \\
\text { project management efficiency, fatigue, and familiarity with } \\
\text { job type }\end{array}$ \\
Operational (discrete) & $\begin{array}{l}\text { Overtime, rework, crew size, work quantity, lack of available } \\
\text { material, change order, and lack of equipment }\end{array}$ \\
\hline
\end{tabular}

Labor productivity is affected by both context and operational parameters. Here, context is referred to by factors with a continuous behavior over time and includes context factors such as weather conditions, fatigue, learning curve, etc. Context variables have complex inter-relationships that can reinforce their effects on the value of labor productivity. The complex inter-related structure of different context parameters can be captured by a system dynamics model that will be introduced in the next section.

In contrast, operational parameters are indicants of process related factors such as sequence of operations, number of resources, resource assignment scheme of the processes, etc., which affect the duration of executing the process and, consequently, the productivity. DES can be implemented to model the operational variables and their effects on labor productivity. The previous studies did not account for both the discrete and continuous parameters (operational and context variables).

In this study, a questionnaire survey was conducted with 80 experts and practitioners to identify different factors affecting labor productivity in construction projects. 26 responses were received, of which 5 were not applicable. Table 2 depicts different factors affecting labor productivity. As shown in Table 2, the influencing factors have been classified into two groups. The variables that are related to operational level, including overtime, rework, crew size, work quantity, lack of available material, change order, and lack of equipment, are considered as discrete factors. The context parameters such as supervision, weather conditions, job complexity, lack of working area, labor experience (skillfulness), motivation, project management efficiency, fatigue, and familiarity with job type are categorized as continuous factors.

\subsection{Hybrid model of influencing factors on labor productivity}

The effects of different continuous factors affecting labor productivity can be captured by System Dynamics (SD). However, it can lead to unrealistic representation of discrete construction operations [23]. On the other hand, Discrete Event Simulation (DES), which has been introduced as the most suitable tool for modeling of project processes, has a limited ability to model the complex inter-related structure of continuous influencing factors due to its discrete event-oriented nature. Compared with DES's emphasis on input randomness, SD's emphasis on the system structure (i.e., feedback process) bolsters the understanding of the system [21]. It is believed that more accurate results in productivity estimation would be obtained when operation and context are taken into account simultaneously for a comprehensive understanding of large-scale construction [21].

The operational parameters such as work in process, number of workers, and work done will be calculated in the DES part of the model. On the other hand, continuous variables such as productivity and required time to complete the process are determined in SD part of the model and can be sent to the DES part as input. The hybrid model structure is explained in more detail in the case example presented below.

\section{Model application: Simulation of labor productivity in a concreting process}

The proposed hybrid SD-DES model was implemented in a real construction project to simulate the labor productivity considering the effects of both contexts and operational influencing factors. This project case example is related to a concreting process consisting of three main operations. Data used for developing $\mathrm{SD}$ and DES models were collected from the real construction site.

\subsection{Case description}

The concreting process consists of three main operations, namely, concrete pouring, vibrating, and finishing works. A resource pool of workers is allocated for each operation. Two pumping workers, one vibrator, and one finisher are allocated for concrete pouring, vibrating, and finishing works, respectively. The workday length is eight hours.

\subsection{System Dynamics (SD) simulation modeling of the labor productivity}

As the first phase of developing the proposed hybrid SD-DES model, the influencing factors on labor productivity were identified and classified into discrete 


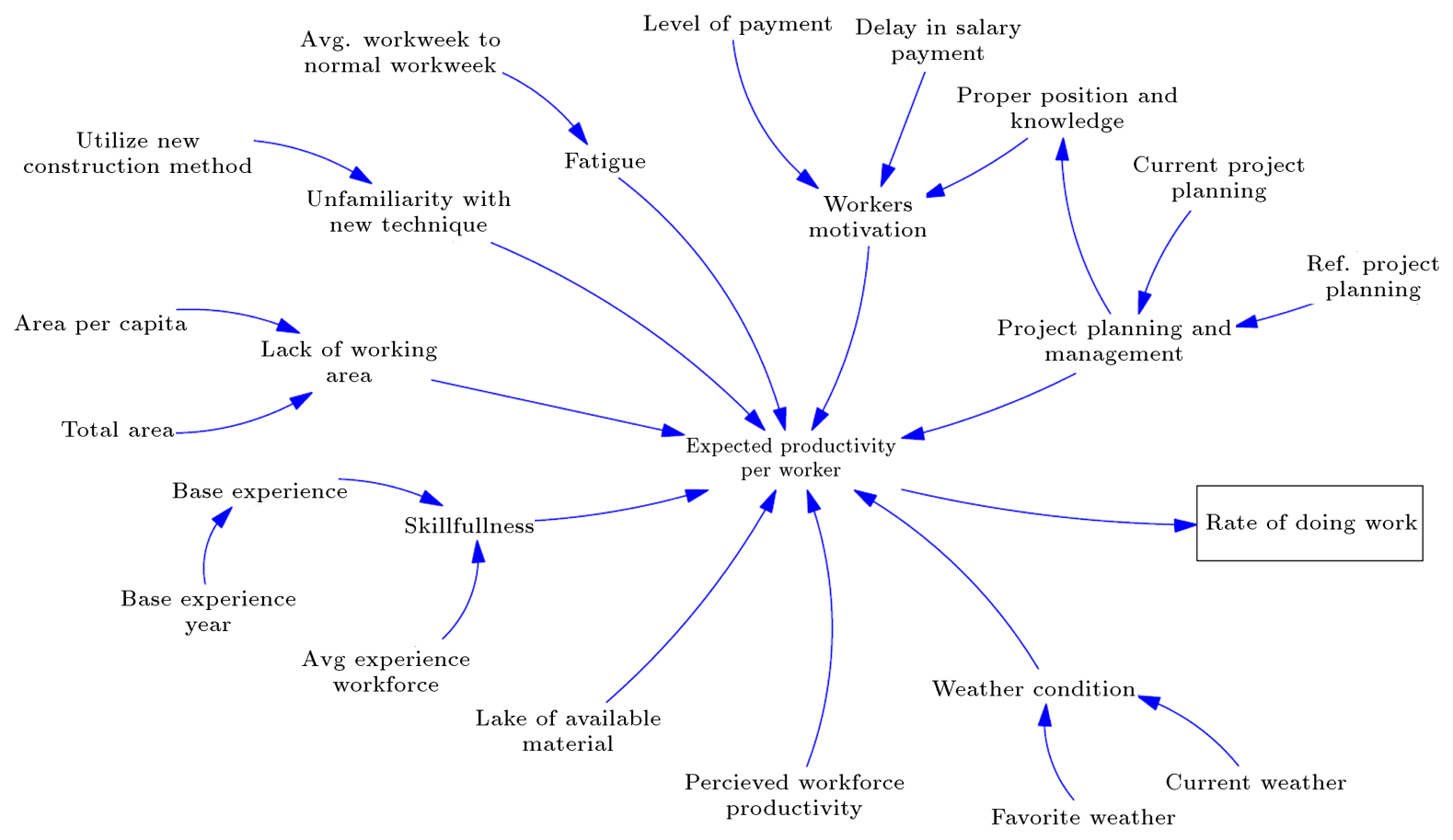

Figure 3. SD model of the labor productivity (adopted from [2]).

variables (operation) and continuous variables (context) as shown in Table 2. The discrete and continuous variables could be modeled by DES and SD simulation schemes, respectively.

Figure 3 depicts the SD model of labor productivity. As shown in this figure, the labor productivity is affected by various context influencing factors. The SD model has been adopted from [2] and slightly modified to be used in the proposed hybrid modeling structure.

As shown in Figure 3, the labor productivity is affected by various factors negatively and positively. Some factors such as skillfulness, worker's motivation, and project planning and management affect labor productivity positively. However, there exist some other factors such as fatigue, lack of working area, and lack of available material that affect labor productivity negatively. The complex interactions that exist between these factors have also been shown in Figure 3. For example, project planning and management that affects labor productivity is influenced by two factors, including reference project planning and current project planning.

\subsection{Discrete Event Simulation (DES) modeling of the labor productivity}

The labor productivity is influenced by operational variables (discrete variables) in addition to the context variables. These operational variables are modeled in DES part of the proposed hybrid model. Figure 4 represents the DES model of concreting process. The concreting process consists of three operations including pouring, vibrating, and finishing works (Figure 4).

In the DES model, each cubic meter of concrete is considered as an entity. The capacity of trucks that transport concrete from batching plant to the site is considered to be $7 \mathrm{~m}^{3}$. It is obvious that while one truck has not finished pouring operation, the other trucks that reach the site afterwards must stay in a queue. In addition, when pouring operation is delayed, the workers allocated to the two subsequent tasks, i.e. vibrating and finishing, will have no work to do. To develop DES model of the concreting process, the required data were gathered from a real concreting project and probability distributions of duration of operations were determined. Finally, duration of the

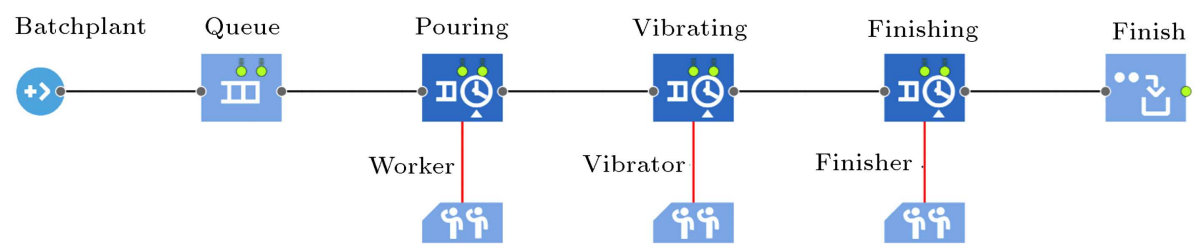

Figure 4. DES model of a concreting process. 
process, resource utilization, work in process, and volume of concreting (work done) were calculated by DES model.

\subsection{Hybrid SD-DES modeling of the labor productivity}

Having constructed the SD and DES models, the hybrid model of labor productivity can be developed. For this purpose, the interaction points and the data exchange mechanism should be defined. Table 3 shows the interaction points between SD and DES models. Variables such as "rate of doing work" are calculated in the SD model and act as inputs to the DES part of hybrid model. On the other hand, variables such as "work done" and "number of workers" are determined in DES model and act as inputs to the SD part of hybrid model.

In the SD model, productivity is simulated as a continuous variable considering all the context influencing factors (Figure 3). The simulated value of labor productivity affects the rate of doing work, which acts as an input to the DES model. In the DES model (Figure 4), the duration of operations is determined based on the rate of doing work.

\subsection{Results and discussion}

The proposed hybrid model was implemented in a realworld construction project. In the following section, the simulated values of labor productivity as well as the effects of different influential factors are presented. Using the proposed hybrid SD-DES model, the value of labor productivity can be predicted considering the values of various influencing factors. Table 4 shows predicted values of labor productivity for 4 different cases. The four cases were selected to reveal capabilities of the proposed hybrid simulation model in predicting the labor productivity considering the values of different context and operational level influencing

Table 3. The interaction points between SD and DES models.

\begin{tabular}{ll}
\hline From SD to DES & From DES to SD \\
\hline \multirow{2}{*}{ Rate of doing work } & Work done \\
& Number of workers \\
\hline
\end{tabular}

factors. According to data from case study, in normal condition (base case), the time required for completing concreting operation is 0.2 hour for each cubic meter of concrete. Therefore, the normal productivity can be considered to be $5 \mathrm{~m}^{3}$ per hour. In cases of no. 1 to 3 , the value of labor productivity gradually decreases from the base case value of $5 \mathrm{~m}^{3}$ per hour. The reason is that the skillfulness and the working area decrease and the weather temperature increases in these cases.

Figure 5 shows the variations of the process completion time of each entity against different values of working area index. Working area index is defined as the ratio of the available working area to the required working area. As shown, the value of working area index varies between 1 and 0 , where 1 represents the case in which the available working area is equal to the required working area. When the number of workers exceeds a specified threshold, the value of working area index decreases from 1 and the labor productivity will decline and, consequently, the process completion time of each entity will increase.

As shown in Figure 5, in normal condition that the working area index is equal to 1 , the corresponding duration is estimated to be 0.2 by the proposed hybrid model. When the working area index decreases from 1 to 0.1 , the process completion time of each entity will increase from 0.2 to 0.6 hour. Obviously, simulation of labor productivity by a single DES model leads to unrealistic results since the interference of working crew arising from the lack of working area is not taken into account.

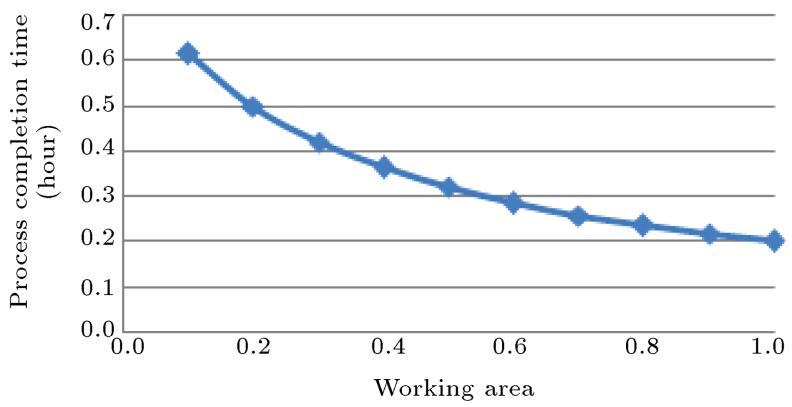

Figure 5. Process completion time of each entity vs. different values of working area index.

Table 4. The simulated values of labor productivity achieved by the proposed hybrid SD-DES model.

\begin{tabular}{ccccccc}
\hline Case number & Skillfulness & $\begin{array}{c}\text { Site } \\
\text { temperature } \\
\left({ }^{\circ} \mathbf{C}\right)\end{array}$ & $\begin{array}{c}\text { Working } \\
\text { area }\end{array}$ & $\begin{array}{c}\text { Number of } \\
\text { workers }\end{array}$ & $\begin{array}{c}\text { Process } \\
\text { completion time } \\
\text { of each } \\
\text { entity (hour) }\end{array}$ & $\begin{array}{c}\text { Productivity } \\
\left(\mathbf{m}^{3} / \mathbf{h}\right)\end{array}$ \\
\hline Base & 1 & 20 & 1 & 4 & 0.2 & 5 \\
1 & 0.9 & 26 & 0.9 & 8 & 0.26 & 3.8 \\
2 & 0.8 & 32 & 0.7 & 9 & 0.38 & 2.6 \\
3 & 0.6 & 40 & 0.6 & 10 & 0.76 & 1.3 \\
\hline
\end{tabular}




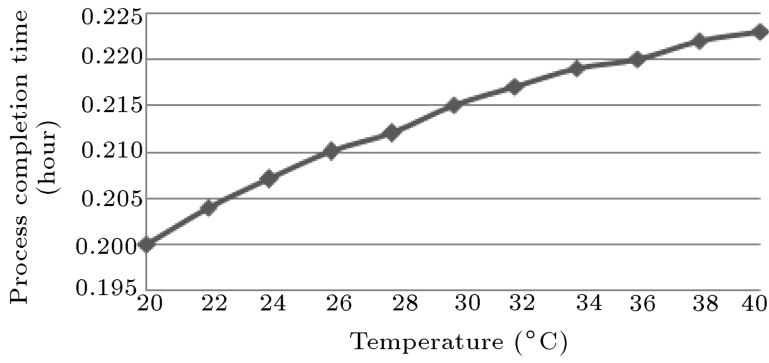

Figure 6. Effect of site temperature fluctuations on process completion time.

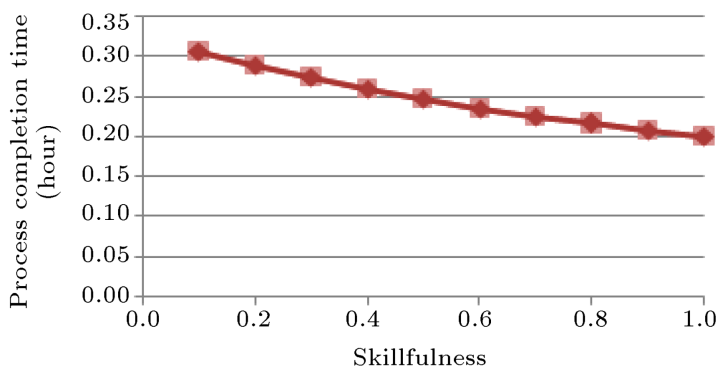

Figure 7. Effect of labor skillfulness on the process completion time.

In the previous section, weather condition was introduced as another important factor affecting the value of labor productivity. In this research, weather condition is regarded as the site temperature that varies during different hours of workday. Figure 6 represents the effect of site temperature fluctuations on process completion time of each entity.

As shown in Figure 6, the process completion time of each entity increases from 0.2 hour to 0.23 hour, corresponding to the site temperatures of $20^{\circ} \mathrm{C}$ and $40^{\circ} \mathrm{C}$, respectively.

Labor skillfulness has been introduced as another context variable affecting the value of labor productivity and the process completion time of each entity. Skillfulness is determined based on the ratio of the current work experiences of the labor to the minimum required work experiences [2]. Figure 7 represents the effect of labor skillfulness on the process completion time of each entity.

As shown, when skillfulness is equal to 1 , the process completion time of each entity corresponds to 0.2 hour. As the skillfulness decreases from 1 to 0.1 , the process completion time of each entity escalates and reaches a maximum value of 0.3 hour.

Finally, the performance of the proposed hybrid SD-DES model is compared with a DES simulation model and the real case results of a concreting operation. As shown in Table 5, using a single DES model, the value of work done is predicted as $154 \mathrm{~m}^{3}$ of concrete pouring. However, using the proposed hybrid SD-DES model, it is revealed that the produced results of DES are over-estimated and the value of work done
Table 5. Comparison between the simulated values achieved by DES and the proposed hybrid SD-DES model.

\begin{tabular}{|c|c|c|}
\hline DES & $\begin{array}{c}\text { Proposed } \\
\text { hybrid } \\
\text { SD-DES }\end{array}$ & $\begin{array}{l}\text { Real } \\
\text { case }\end{array}$ \\
\hline
\end{tabular}

Productivity of

concreting operation $\left(\begin{array}{llll}\mathbf{m}^{\mathbf{3}} & 154 & 147 & 145\end{array}\right.$

in an 8-hour workday)

would be limited to $147 \mathrm{~m}^{3}$ of concrete pouring, which is more realistic than the performance achieved by real case outputs. It is believed that using the proposed hybrid SD-DES model, the value of labor productivity can be simulated more precisely since both the context and operational level influencing factors are taken into account.

\section{Conclusions and remarks}

A hybrid SD-DES approach was presented to simulate the value of labor productivity considering the effects of both continuous (context) and discrete (operational) influencing variables. System Dynamics (SD) approach accounted for the highly dynamic complex inter-related structure of different context factors. On the other hand, Discrete Event Simulation (DES) was used for simulating the work processes and operational influencing factors. The required steps to develop the hybrid SD-DES model and synchronize SD and DES methods were illustrated.

The applicability and performance of the proposed hybrid model were assessed by implementing it in a real world project. It was shown that how the value of labor productivity could be predicted considering all the context and operational level influencing factors. A sensitivity analysis was finally conducted to evaluate the effect of different influencing factors on labor productivity. The results of the sensitivity analysis revealed that how the labor productivity was affected by different influencing factors such as working area, weather temperature, and skillfulness. The proposed hybrid SD-DES method may present a novel and robust approach to simulate the value of labor productivity since the effects of both context and operational level influencing factors are taken into account.

\section{References}

1. Hanna, A.S., Taylor, C.S. and Sullivan, K.T. "Impact of extended overtime on construction labor productivity", Journal of Construction Engineering and Management, 131(6), pp. 734-740 (2005).

2. Nasirzadeh, F. and Nojedehi, P. "Dynamic modeling of labor productivity in construction projects", International Journal of Project Management, 31(6), pp. 903-911 (2013). 
3. Nojedehi, P. and Nasirzadeh, F. "A hybrid simulation approach to model and improve construction labor productivity", KSCE Journal of Civil Engineering, 21(5), pp. 1516-1524 (2017).

4. Song, L. and AbouRizk, S.M. "Measuring and modeling labor productivity using historical data", Journal of Construction Engineering and Management, 134(10), pp. 786-794 (2008).

5. Horner, R.M.W., Talhouni, B.T. and Thomas, H.R. "Preliminary results of major labour productivity monitoring programme", Proceedings of the 3rd Yugoslavian Symposium on Construction Management, Cavtat, Croatia, pp. 18-28 (1989).

6. Jarkas, A. and Bittar, C. "Factors affecting construction labor productivity in Kuwait", Journal of Construction Engineering and Management, 138(7), pp. 811-820 (2012).

7. Jang, H., Kim, K., Kim, J. and Kim, J. "Labour productivity model for reinforced concrete construction projects", Construction Innovation: Information, Process, Management, 11(1), pp. 92-113 (2011).

8. Zayed, T.M. and Halpin, D.W. "Productivity and cost regression models for pile construction", Journal of Construction Engineering and Management, 131(7), pp. 779-789 (2005).

9. Pan, N.F. "Assessment of productivity and duration of highway construction activities subject to impact of rain", Journal of Expert Systems with Application, 28, pp. 313-326 (2005).

10. Watkins, M., Mukherjee, A., Onder, N. and Mattila, K. "Using agent-based modeling to study construction labor productivity as an emergent property of individual and crew interactions", Journals of Construction Engineering and Management, 135(7), pp. 657-667 (2009).

11. Goodrum, P.M., Zhai, D. and Yasin, F. "Relationship between changes in material technology and construction productivity", Journal of Construction Engineering and Management, 135(4), pp. 278-287 (2009).

12. Goodrum, P.M., Haas, T., Caldas, C., Zhai, D., Yeiser, J. and Homm, D. "Model to predict the impact of a technology on construction productivity", Journal of Construction Engineering and Management, 137(9), pp. 678-688 (2011).

13. Mawdesley, M.J. and Al-Jibouri, S. "Modelling construction project productivity using systems dynamics approach", International Journal of Productivity and Performance Management, 59(1), pp. 18-36 (2010).

14. Alvanchi, A., Lee, Y.H. and AbouRizk, S. "Dynamics of working hours in construction", Journal of Construction Engineering and Management, 138(1), pp. 114-122 (2012).

15. Forcael, E., González, V., Ellis, R. and Orozco, F. "Conceptual methodology for managing transportation construction projects through the use of buffer- ing strategies", 9th LACCEI Latin American and Caribbean Conference, Medellín, Colombia (2011).

16. Forrester, J.W. "Industrial dynamics", Pegasus Communications, Waltham, MA (1961).

17. Khanzadi, M., Nasirzadeh, F. and Alipour, M. "Integrating system dynamics and fuzzy logic modeling to determine concession period in BOT projects", Journal of Automation in Construction, 22, pp. 368376 (2012).

18. Nasirzadeh, F., Khanzadi, M. and Rezaie, M. "System dynamics approach for quantitative risk allocation", International Journal of Industrial Engineering 83 Production Research, 24(3), pp. 237-246 (2013).

19. Nasirzadeh, F., Rouhparvar, M., Mazandarani Zadeh, H. and Rezaie, M. "Integrating system dynamics and fuzzy bargaining for quantitative risk allocation in construction projects", Scientia Iranica, 22(3), pp. $668-678(2015)$.

20. Sterman, J.D., Business Dynamics: Systems Thinking and Modeling for a Complex World, McGraw-Hill, USA (2000).

21. Lee, S., Han, S. and Pena-Mora, F. "Integrating construction operation and context in large-scale construction using hybrid computer simulation", Journal of Computing in Civil Engineering, 23(2), pp. 75-83 (2009).

22. Alvanchi, A., Lee, Y.H. and AbouRizk, S. "Modeling framework and architecture of hybrid system dynamics and discrete event simulation for construction", Computer-Aided Civil and Infrastructure Engineering, 26(2), pp. 77-91 (2011).

23. Lee, S., Han, S. and Pena-Mora, F. "Hybrid system dynamics and discrete event simulation for construction management", ASCE International Workshop on Computing in Civil Engineering, Pittsburgh, PA. pp. 232-239 (2007).

24. Peña-Mora, F., Han, S., Lee, S.H. and Park, M. "Strategic-operational construction management: hybrid system dynamics and discrete event approach", Journal of Construction Engineering and Management, 134(9), pp. 701-710 (2008).

25. Moradi, S., Nasirzadeh, F. and Golkhoo, F. "A hybrid SD-DES simulation approach to model construction projects", Construction Innovation: Information, Process, Management, 15(1), pp. 66-83 (2015).

26. Pritsker, A., O'Reilly, J. and LaVal, D., Simulation with Visual SLAM and AweSim, John Wiley \& Sons, USA (1997).

27. Lim, E. C. and Alum, J. "Construction productivity: issues encountered by contractors in Singapore", International Journal of Project Management, 13(1), pp. 51-58 (1995). 
28. Zakeri, M., Olomolaiye, P.O., Holt, G.D. and Harris, F.C. "A survey of constraints on Iranian construction operatives' productivity", Journal of Construction Management and Economics, 14(5), pp. 417-426. (1996).

29. Kaming, P.F., Olomolaiye, P.O., Holt, G.D. and Harris, F.C. "Factors influencing construction time and cost overruns on high-rise projects in Indonesia", Construction Management and Economics, 15(1), pp. 83-94 (1997).

30. Sonmez R. and Rowings J.E. "Construction labor productivity modeling with neural networks", Journal of Construction Engineering and Management, 124(6), pp. 498-504 (1998).

31. Hanna, A.S., Russell, J.S., Gotzion, T.W. and Nordheim, E.V. "Impact of change orders on labor efficiency for mechanical construction", Journal of Construction Engineering and Management, 125(4), pp. 176-184 (1999).

32. Enshassi, A., Mohamed, S., Abu Mustafa, Z. and Mayer, P.E. "Factors affecting labour productivity in building projects in the Gaza strip", Journal of Civil Engineering and Management, 13(4), pp. 245-254 (2007).

\section{Biographies}

Saeed Moradi received his MSc degree in Project and Construction Management from Tarbiat Modares University (TMU), Tehran, Iran, in 2012. He is currently $\mathrm{PhD}$ student at Concordia University, Montreal, Canada. His research interests include labor productivity in construction, simulation of construction processes, and infrastructure management.

Farnad Nasirzadeh received his $\mathrm{MSc}$ and $\mathrm{PhD}$ degrees in Construction Engineering and Management from Iran University of Science and Technology, Tehran, Iran. He is currently an Associate Professor in the Department of Civil Engineering at Payame Noor University (PNU). His research interests include project risk management and modeling and simulation of construction projects.

Farzaneh Golkhoo received her MSc degree in Project and Construction Management from Tarbiat Modares University (TMU), Tehran, Iran, in 2012. She is currently PhD student at Concordia University, Montreal, Canada. Her research interests include construction process simulation, construction 3D modeling, and material management. 